\title{
A Comparative Study of Outcomes in Management of Breast Abscess by Ultrasound Guided Needle Aspiration and Incision and Drainage
}

\author{
Shruti K Somani ${ }^{1}$, Rekha Porwal' ${ }^{2}$, Amit Singh ${ }^{3}$, Aakanksha Soni ${ }^{4}$, Poornima Sagar \\ ${ }^{1}$ Postgraduate Resident, ${ }^{2}$ Senior Professor, ${ }^{3}$ Assistant Professor, ${ }^{4}$ Postgraduate Resident, ${ }^{5}$ Postgraduate Resident, \\ Department of General Surgery, J.L.N Medical College Ajmer, Rajasthan. 305001.
}

\begin{abstract}
Background- Breast abscess is a common cause of morbidity in women. While they are less common in developed countries as a result of improved maternal hygiene, nutrition, standard of living and early administration of antibiotics, breast abscess remain a problem among women in developing countries.

Methods- Hospital based prospective randomized controlled study conducted on 100 patients. Fifty of them were randomized in the aspiration group and other 50 were treated by incision and drainage. All statistical analysis was done in Epi-info statistical software.

Results- Majority of the patients were of the age group 21-30 years. History of lactation was present in 66\% of the cases. Staphylococcus aureus is the most common organism responsible for breast abscess. Patients of needle aspiration group encountered lesser pain than the incision and drainage group.

Conclusion- Wherever the facility of ultrasound is available, serial percutaneous needle aspiration may be tried as a first line of therapy up to a maximum of three attempts, in patients whose abscess diameter $<5 \mathrm{~cm}$ and in those where the abscess diameter is $>5 \mathrm{~cm}$, incision and drainage maybe used as first line therapy.
\end{abstract}

Keywords- Needle aspiration, Incision and drainage, Breast abscess.

\section{Introduction}

Acute inflammation of the breast usually occurs in lactating women and to a lesser extent in non lactating women that is attributed to the increased activity of the breast tissue in response to female hormones. It may range from mild superficial mastitis to deep abscess. The most commonly implicated organism is Staphylococcus aureus ${ }^{1}$.

Lactational breast abscess occurring during breast feeding is the result of Staphylococcus infection, affecting $0.4-11 \%$ of lactating females ${ }^{2}$. Such abscesses

\section{Corresponding author*:}

\section{Amit Singh}

Assistant Professor, Department Of General Surgery, J.L.N Medical College, Ajmer, Rajasthan

Phone: +919460387152,

Email: dr.amit5280@gmail.com tend to occur at the commencement of breast feeding when an inexperienced mother developed cracked nipples. They also occur at weaning when engorgement results from incomplete drainage of breast milk.

Non-lactational breast abscesses are entirely different from those occurring during breast feeding. The true incidence of this condition in non-lactating females is not knows and is estimated to be $1-33 \%^{3}$. They occur in the peri-areolar tissues, frequently recur, and infecting organisms are a mixture of bacteroides, anaerobic streptococci, and enterococci. Such nonlactational breast abscess is a manifestation of duct ectasia/periductal mastitis and is usually seen in the age group 30-60 years.

High-Resolution real-time sonography is a unique means of diagnosing and evaluating the extent, site, size and internal characteristics of breast abscesses. Whereas diagnosis has never been a problem, increased 
cosmetic concern due to changing social values has caught treating physician in a great dilemma. Traditional treatment of breast abscess is by surgical incision and drainage. Treating breast abscesses in lactating women by aspiration is not new ${ }^{1}$.Imaging guided percutaneous needle aspiration of purulent collections is a known alternative to standard treatment which has become more popular as it is less invasive, cosmetically better and can be managed entirely on outpatient basis as compared to incision and drainage ${ }^{2}$.

The present study tries to compare the two treatment modalities ultrasound guided needle aspiration and incision and drainage and assess their outcome in patients with breast abscess.

\section{Materials and Method}

The present study was conducted on the patients presenting with breast abscess in surgical outdoor in various surgical units in Department of General Surgery, J.L.N Medical college and Associated Group of Hospitals, Ajmer.

\section{Study design:}

This was a hospital based prospective randomized controlled study.

\section{Sample size:}

100 patients were included in the study. 50 of them were randomized in the aspiration group and other 50 were treated by incision and drainage.

\section{Inclusion Criteria:}

All women above 18 years of age and below 45 years of age

\section{Exclusion Criteria:}

1. Patients with recurrent abscesses.

2. Breast abscess with signs of impending rupture.

3. Breast abscess with necrotic skin overlying the abscess

4. Breast abscess already draining

5. Patients with clinical features of immune suppression (WHO stage 3 and stage 4)

6. Patients known to be allergic to penicillin antibiotics.

\section{Methodology:}

Clinical diagnosis was made based on the presence of a fluctuant tender breast swelling. Patients were then subjected to USG scan (high frequency linear transducer of 7.5MHZ) in radiology department. The diagnosis was confirmed ultrasonographically by the presence of a thick-walled echo complex mass, predominantly cystic with internal echoes and septations.

Patients were then randomly divided into two groups by computer generated randomization table. A written informed consent was taken from all patients included in the study.

Group A: ultrasound guided needle aspiration

Group B: incision and drainage of breast abscess

Complete history was taken and general physical examination was done.

Routine blood investigations like hemogram, renal function tests and coagulation profile, random blood sugar were done. A primary ultrasonography of the breast was done at time of admission for abscess size, location and number.

\section{Follow Up}

The patients were follow up on days $3,7,14,21$ post intervention and thereafter for three months on a monthly basis.

\section{Data Analysis}

To collect required information from eligible patients a pre-structured pre-tested Proforma will be used. For data analysis Microsoft excel and statistical software SPSS will be used and data will be analyzed with the help of frequencies, figures, proportions, measures of central tendency, appropriate statistical test.

\section{Results}

In both groups, majority of patients were within the age group of $21-30$ years, $46 \%$ in the needle aspiration group and $54 \%$ in the incision and drainage group. The mean age of patients in our study was 27.90 years. The mean age in incision and drainage group was 26 years, and in needle aspiration group, it was 29 years. The difference in age group between the 2 groups was statistically Insignificant. [Figure 1] 
In our study, overall, out of 100 patients, $66(66 \%)$ were lactating and 34 (34\%) were non-lactating. In I\&D group 37 patients $(74 \%)$ were lactating and 13 patients (26\%) were non-lactating. In needle aspiration group, 29 patients $(58 \%)$ were lactating and 21 patients $(42 \%)$ were non-lactating. The difference in lactational status between 2 groups was statistically Insignificant.[Table1]

In our study, overall, 49 patients (49\%) had sterile cultures, and in 51 patients (51\%) staphylococcus aureus was isolated. In these 51 patients, 30 patients has staphylococcus aureus and 21 patients had MRSA in their cultures. In I\&D group, 19 patients (38\%) had staphylococcus aureus in their culture, 17 patients (34\%) had sterile culture, and 14 patients (28\%) had MRSA in their cultures. In needle aspiration group, 32 patients (64\%) had sterile cultures, 11 patients $(22 \%)$ had staphylococcus aureus in their cultures and 7 patients (14\%) had MRSA in their cultures. [Table2]

In our study, out of 50 patients in needle aspiration group , 13 patients (26\%) had abscess cavity of diameter up to $2.5 \mathrm{~cm}, 29$ patients (58\%) had abscess cavity of 2.6-5 $\mathrm{cm}$ and 8 patients (16\%) had abscess cavity of diameter $>5 \mathrm{~cm}$. And out of 50 patients, 9 patients $(18 \%)$ had abscess cavity of diameter up to $2.5 \mathrm{~cm}, 32$ patients
(64\%) had abscess cavity of diameter $2.6-5 \mathrm{~cm}$ and 9 patients $(18 \%)$ had abscess cavity of diameter $>5 \mathrm{~cm}$. This difference in diameter of abscess cavity between needle aspiration and I\&D group was statistically Insignificant. [Table 3]

In our study, out of 50 patients in needle aspiration group, the duration of hospital stay was 1 day in 3 patient $(6 \%), 2$ days in 27 patients (54\%), 3 days in 13 patients $(26 \%), 4$ days in 7 patients (14\%). Out of 50 patients in I\&D group, the duration of hospital stay was 2 days in 13 patients (26\%), 3 days in 23 patients (46\%), 4 days in 11 patients $(22 \%)$ and 5 days in 3 patients $(6 \%)$. This difference in duration of hospital stay between 2 groups was statistically significant. [Table 4]

In our study, patients in the needle aspiration group had lesser pain as compared to the patients of the incision and drainage group. Average pain score (on visual analogue scale) on day three of patients in the needle aspiration group was 4.25 as compared to 5.75 in the incision and drainage group. On day seven the pain score was 1.75 in the aspiration group and 3.91 in the incision and drainage group. By day fourteen almost all patients $(91.6 \%)$ of needle aspiration group were pain free and the average pain score in the incision and drainage group was 2.0. [Table 5]

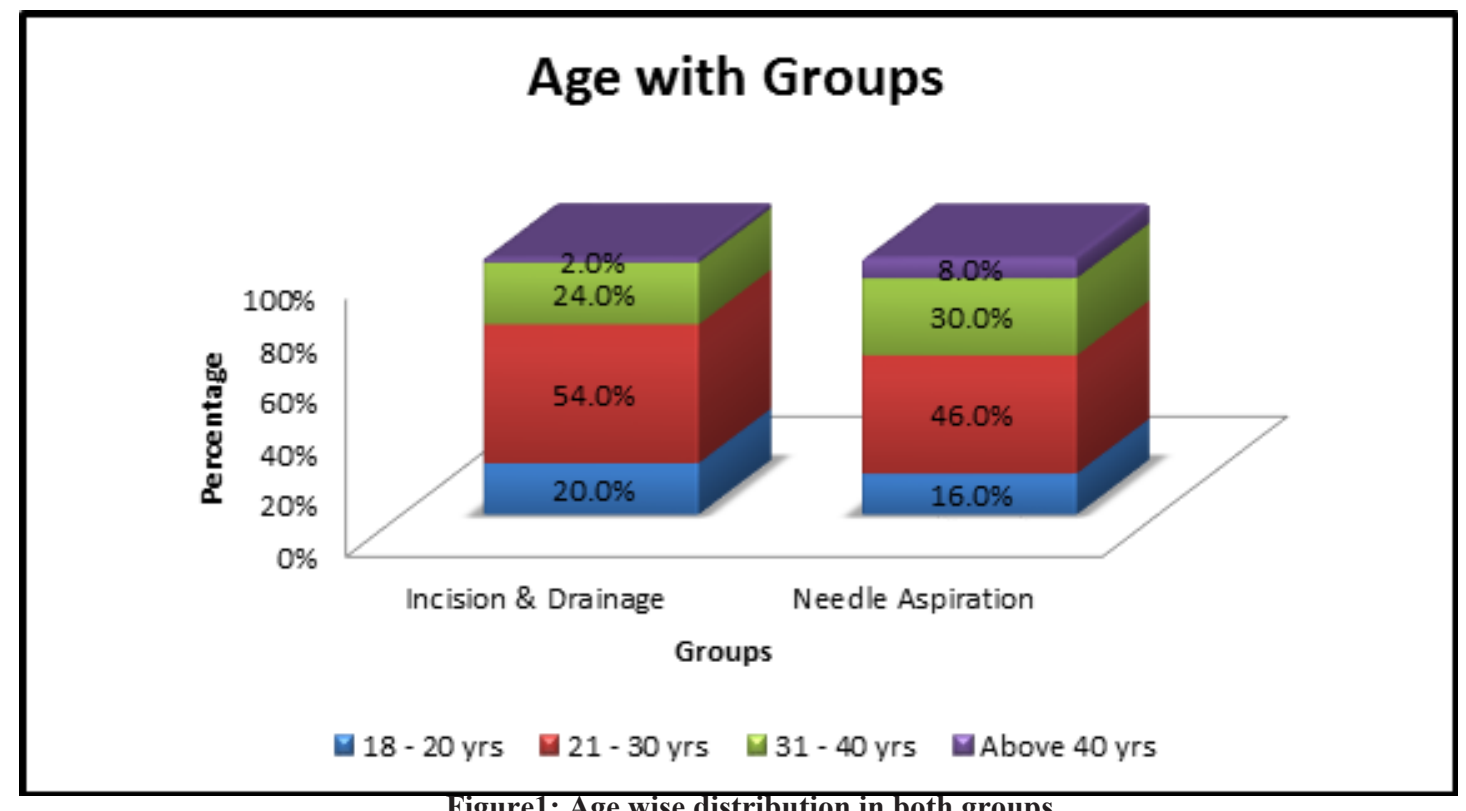

Figure1: Age wise distribution in both groups. 
Table 1: Lactational status

\begin{tabular}{|c|c|c|c|c|c|}
\hline \multicolumn{3}{|l|}{$\begin{array}{l}\text { I \& D } \\
\text { NA }\end{array}$} & \multicolumn{2}{|l|}{ Groups } & \multirow{2}{*}{\begin{tabular}{|l|} 
Total \\
34 \\
\end{tabular}} \\
\hline \multirow{4}{*}{ LACTATIONAL STATUS } & \multirow{2}{*}{ NO } & Count & 13 & 21 & \\
\hline & & $\%$ & $26.0 \%$ & $42.0 \%$ & $34.0 \%$ \\
\hline & \multirow{2}{*}{ YES } & Count & 37 & 29 & 66 \\
\hline & & $\%$ & $74.0 \%$ & $58.0 \%$ & $66.0 \%$ \\
\hline \multirow{2}{*}{\multicolumn{2}{|c|}{$\begin{array}{l}\text { Total } \\
\%\end{array}$}} & Count & 50 & 50 & 100 \\
\hline & & $100.0 \%$ & $100.0 \%$ & $100.0 \%$ & \\
\hline
\end{tabular}

Table 2: Microbiological profile

\begin{tabular}{|c|c|c|c|c|c|}
\hline \multirow{2}{*}{$\begin{array}{l}\text { I \& D } \\
\text { NA }\end{array}$} & & & \multicolumn{2}{|l|}{ Groups } & \multirow{3}{*}{\begin{tabular}{|l} 
Total \\
21 \\
\end{tabular}} \\
\hline & & & & & \\
\hline \multirow{6}{*}{$\begin{array}{l}\text { MICROBIOLOGICAL } \\
\text { PROFILE }\end{array}$} & MRSA & Count & 14 & 7 & \\
\hline & & $\%$ & $28.0 \%$ & $14.0 \%$ & $21.0 \%$ \\
\hline & $\begin{array}{l}\text { staphylococcus } \\
\text { aureus }\end{array}$ & Count & 19 & 11 & 30 \\
\hline & & $\%$ & $38.0 \%$ & $22.0 \%$ & $30.0 \%$ \\
\hline & sterile & Count & 17 & 32 & 49 \\
\hline & & $\%$ & $34.0 \%$ & $64.0 \%$ & $49.0 \%$ \\
\hline \multirow{2}{*}{\multicolumn{2}{|c|}{$\begin{array}{l}\text { Total } \\
\%\end{array}$}} & Count & 50 & 50 & 100 \\
\hline & & $100.0 \%$ & $100.0 \%$ & $100.0 \%$ & \\
\hline
\end{tabular}

Table 3: Diameter of abscess cavity:

\begin{tabular}{|c|c|c|c|c|c|}
\hline \multirow{2}{*}{\multicolumn{3}{|c|}{$\begin{array}{l}\text { I \& D } \\
\text { NA }\end{array}$}} & \multicolumn{2}{|l|}{ Groups } & \multirow{3}{*}{$\begin{array}{l}\text { Total } \\
22\end{array}$} \\
\hline & & & & & \\
\hline \multirow{6}{*}{$\begin{array}{l}\text { DIAMETER OF ABSCESS } \\
\text { CAVITY(CM) }\end{array}$} & \multirow{2}{*}{$\begin{array}{l}\text { Upto } 2.5 \\
\mathrm{~cm}\end{array}$} & Count & 9 & 13 & \\
\hline & & $\%$ & $18.0 \%$ & $26.0 \%$ & $22.0 \%$ \\
\hline & \multirow{2}{*}{$\begin{array}{l}2.6-5 \\
\mathrm{cms}\end{array}$} & Count & 32 & 29 & 61 \\
\hline & & $\%$ & $64.0 \%$ & $58.0 \%$ & $61.0 \%$ \\
\hline & \multirow{2}{*}{$\begin{array}{l}\text { Above } 5 \\
\text { cms }\end{array}$} & Count & 9 & 8 & 17 \\
\hline & & $\%$ & $18.0 \%$ & $16.0 \%$ & $17.0 \%$ \\
\hline \multirow{2}{*}{\multicolumn{2}{|c|}{$\begin{array}{l}\text { Total } \\
\%\end{array}$}} & Count & 50 & 50 & 100 \\
\hline & & $100.0 \%$ & $100.0 \%$ & $100.0 \%$ & \\
\hline
\end{tabular}


Table 4: Duration of hospital stay

\begin{tabular}{|c|c|c|c|c|c|}
\hline \multirow{2}{*}{$\begin{array}{l}\text { I \& D } \\
\text { NA }\end{array}$} & & & \multicolumn{2}{|l|}{ Groups } & \multirow{3}{*}{$\begin{array}{l}\text { Total } \\
3\end{array}$} \\
\hline & & & & & \\
\hline \multirow{10}{*}{$\begin{array}{l}\text { Duration of hospital } \\
\text { stay (Days) }\end{array}$} & \multirow{2}{*}{1} & Count & 0 & 3 & \\
\hline & & $\%$ & $0.0 \%$ & $6.0 \%$ & $3.0 \%$ \\
\hline & \multirow{2}{*}{2} & Count & 13 & 27 & 40 \\
\hline & & $\%$ & $26.0 \%$ & $54.0 \%$ & $40.0 \%$ \\
\hline & \multirow{2}{*}{3} & Count & 23 & 13 & 36 \\
\hline & & $\%$ & $46.0 \%$ & $26.0 \%$ & $36.0 \%$ \\
\hline & \multirow{2}{*}{4} & Count & 11 & 7 & 18 \\
\hline & & $\%$ & $22.0 \%$ & $14.0 \%$ & $18.0 \%$ \\
\hline & \multirow{2}{*}{5} & Count & 3 & 0 & 3 \\
\hline & & $\%$ & $6.0 \%$ & $0.0 \%$ & $3.0 \%$ \\
\hline \multirow{2}{*}{\multicolumn{2}{|c|}{$\begin{array}{l}\text { Total } \\
\%\end{array}$}} & Count & 50 & 50 & 100 \\
\hline & & $100.0 \%$ & $100.0 \%$ & $100.0 \%$ & \\
\hline
\end{tabular}

Table 5: Average pain score

\begin{tabular}{|l|l|l|}
\hline \multicolumn{2}{|l|}{ Average pain score (10) } \\
\hline Day & Needle aspiration Group & Incision and drainage group \\
\hline 3 & $4.25 \pm 2.84$ & $5.75 \pm 1.84$ \\
\hline 7 & $1.75 \pm 2.96$ & $3.91 \pm 2.22$ \\
\hline 14 & $0.25 \pm 1.65$ & $2 \pm 2.45$ \\
\hline 21 & 0 & 0 \\
\hline 30 & 0 & 0 \\
\hline 60 & 0 & 0 \\
\hline 90 & 0 & 0 \\
\hline
\end{tabular}

\section{Discussion}

The breast is one of the sex organs of a female, in case of breast disease care should be taken to insure that its beauty is minimally compromised in order to preserve its value and function. Despite of breast abscess becoming less in developed countries due to improved maternal hygiene, nutrition, standard of living and early use of antibiotics, breast abscess remain a problem among women in developing countries ${ }^{4}$.

Treatment of breast abscess traditionally has been incision and drainage however this has been found to be associated with possible unsatisfactory cosmetic outcome, difficult in breast feeding and needs general anesthesia, prolonged healing time, and regular dressing 5. Repeated aspiration with or without ultrasound guidance has been found to be another treatment 
option for breast abscess and this has been reported to be associated with less recurrence, excellent cosmetic result and has less costs ${ }^{6-8}$

In our study, overall, 49 patients (49\%) had sterile cultures, and in 51 patients (51\%) staphylococcus aureus was isolated. In these 51 patients, 30 patients have staphylococcus aureus and 21 patients had MRSA in their cultures. In I\&D group, 19 patients (38\%) had staphylococcus aureus in their culture, 17 patients (34\%) had sterile culture, and 14 patients (28\%) had MRSA in their cultures. In needle aspiration group, 32 patients (64\%) had sterile cultures, 11 patients (22\%) had staphylococcus aureus in their cultures and 7 patients (14\%) had MRSA in their cultures.

It was noted that $58 \%$ of the females in the needle aspiration group and $74 \%$ of patients in the incision and drainage group were lactational suggested that stasis of milk and carrier state of the infant plays a key role in the development of breast abscess. This is comparable with the finding of Singh et $\mathrm{al}^{9}$ where out of fifty patients $62 \%$ were lactational and $38 \%$ were non lactational. However, in a study done by Elagili et a $1^{10} 53.3 \%$ of patient were seen to be non lactational and $46.7 \%$ were lactational. This fact may be explained by better maintenance of maternal hygiene.

The bacteriological cultures that were sent revealed that $51 \%$ of the samples grew Staphylococcus aureus and the rest $49 \%$ were sterile. This shows the exclusive prevalence of Staphylococcus aureus as the causative organism in the breast abscess. The high percentage of sterile cultures can be explained by the fact that most patients presenting to our hospital have already taken a course of antibiotics prior of presentation. Out of the 51samples that showed staphylococcal growth 21 strains were methicillin resistant (MRSA). Dabbas et al observed one hundred and ninety patients of breast abscess and reported Staphylococcus aureus as the causative organism in $51.3 \%$ cases. Of these $8.6 \%$ were methicillin resistant strains. Ulitzsch et al reported Staphylococcus aureus in $89 \%$ of their patients ${ }^{11}$. In a study conducted by Berna-Serna et $\mathrm{al}^{12}$ with thirty nine patients of breast abscess, fifteen (38.4\%) cases had a sterile cultures and eight (20.5\%) were positive for Staphylococcus aureus. Also, we noted that out of the 66 lactating patients, $38(57.5 \%)$ had Staphylococcus aureus as the bacterial growth. Whereas in the 34 non-lactating females, $21(61.7 \%)$ had a sterile culture. Out of the 30 patients growing Staphylococcus aureus in the culture,
17 (57.1\%) were sensitive to cloxacillin and 13 (42.9\%) were sensitive to co-amoxyclav. All the 21 patients having methicillin resistant Staphylococcus aureus as growth were sensitive to vancomycin.

It was seen that patients in the aspiration group had lesser pain as compared to the patients of the incision and drainage group and hence had a lesser analgesic requirement. Average pain score (on visual analogue scale) on day three of patients in the needle aspiration group was 4.25 as compared to 5.75 in the incision and drainage group. On day seven the pain score was 1.75 in the aspiration group and 3.91 in the incision and drainage group. By day fourteen almost all patients (91.6\%) of needle aspiration group were pain free and the average pain score in the incision and drainage group was 2.0. On comparing the analgesic requirement on day seven it was seen that only 16 out of the 50 patients of the needle aspiration group needed analgesics as compared to 45 patients of incision and drainage group. Using the chi square test, a $p$ value of 0.0005 was obtained suggesting a statistically significant difference. Hence it can be derived that incision and drainage is a more painful procedure as compared to needle aspiration. The delayed persistence of pain can be associated to the open wound in patients undergoing incision and drainage which is not there in cases of needle aspiration.

All patients included in the study were admitted in the hospital for a period ranging from 1-4 days. Average duration of hospital stay in needle aspiration group was 3.08 while in needle aspiration group, it was 2.48 . The difference was found to be statistically significant with a p-value of 0.006 . In the study conducted by Chandika et al all patients that were treated by needle aspiration did not require admission whereas those treated by incision and drainage were admitted for a variable period of two to five days. ${ }^{13}$

\section{Conclusion}

In conclusion it can be said that whenever and wherever the facility of ultrasound is available, serial percutaneous needle aspiration may be tried as a first line of therapy up to a maximum of three attempts, in patients whose abscess diameter $<5 \mathrm{~cm}$ and in those where the abscess diameter is $>5 \mathrm{~cm}$, incision and drainage maybe used as first line therapy.

\section{Conflict of Interest: NIL}

Source of Funding: NIL 
Ethical Clearance: Taken from institution ethical committee of J.L.N Medical College, Ajmer, Rajasthan, India, 305001.

\section{References}

1. Dabbas N, Chand M, Pallett A, Royle GT, Sainsbury R. Have the organism that cause Breast Abscess Changed with time?-Implication for appropriate used in primary and secondary care. The Breast Journal 2010; 16(4):412-5.

2. Marchant DJ. Inflammatory of the breast. Obstetrics and Gynaecology clinics of North America 2002 Mar; 29(1):89-102.

3. Kataria K, Srivastava A, Dhar A. Management of lactational mastitis and breast abscesses: Review of current knowledge and practice. Indian Journal of Surgery 2013 Dec;75(6):430-5.

4. Thomsen AC, Hansen KB, Moller BT. Leucocyte count and microbiological cultivation in the diagnosis of puerperal mastitis. Am J Obst Gynec 1983 Aug 15;146(8):938-41.

5. Haagensen CD. Disease of the Breast. $3^{\text {rd }}$ ed. Philadelphia: WB Saunders; 1986:357-9.

6. Efem SE. Breast abscesses in nigerian women: lactational vs non-lactational women. Journal of Royal College of Surgeons of Edinburgh. 1995 Feb $\therefore 40(1): 25-7$

7. Pluchinotta AM, Catania S. Percutaneous management of peripheral nonlactational breast abscesses. Breast Diseases 1996;9:223-7.

8. Tan SM, Low SC. Non-operative treatment of breast abscesses. The Australian and new Zealand Journal of Surgery.1998 Jun; 68(6):423-4.

9. Singh G, Singh G, Singh LR, Singh R, Singh S, Lekhachandra KS. Management of breast abscess by repeated aspiration and antibiotics. Journal of Medical Society 2012 Sep - Dec; 26(3):189-91

10. Elagili F, Abdullah N, Fong L., Pei T. Aspiration of breast abscess under ultrasound guidance: Outcome obtained and factors affecting success. Asian Journal of Surgery 2007 Jan; 30(1):40-4.

11. Ulitzsch D, Nyman MKG, Carlson AR. Breast abscess in lactating women: US-guided treatment. Radiology 2004;232:904-9.

12. Berna-Serna JD, Madrigal M, Berna-Serna JD Percutaneous management of breast abscesses. An experience of 39 cases. Ultrasound in Medicine and Biology 2004; 30(1):1-6.

13. Chandika AB, Gakwaya AM, Kiguli - Malwadde E, Chalya PL. Ultrasound guided needle aspiration versus surgical drainage in the management of breast abscesses : A Ugandan experience. Biomed Central Research Notes 2012 Jan 6;5(12):1-7. 